\title{
Concrete Durability Probed Using Compressive Strength, Chloride Penetration and Porosity Measurements on CEMII and CEMV Concretes Incorporating Mollusc Shell Spares in Artificial and Natural Seawaters
}

\author{
Marine D. Georges ${ }^{1}$, Amel. Bourguiba ${ }^{1}$, Nassim. Sebaibi ${ }^{1}$, Daniel. Chateigner ${ }^{2}$ and \\ Mohamed. Boutouil ${ }^{1}$
}

${ }^{1}$ COMUE Normandie Université, Laboratoire ESITC - ESITC Caen, rue Pierre et Marie Curie 1, 14610 Epron, France, marine.georges@esitc-caen.fr

${ }^{2}$ Normandie Université, CRISMAT UMR CNRS n6508, ENSICAEN, Université de Caen Normandie, 6 boulevard Maréchal Juin, 14050 Caen, France, daniel.chateigner@ensicaen.fr

\begin{abstract}
The purpose of this study is to improve the recruitment of flat oyster larvae, an endangered species, by means of a specific marine infrastructure made of concrete. This work aims to develop and optimize concrete formulations by varying the type of cement and introducing shellfish by-products into their composition and determine which concrete formulation is the most sustainable to marine organism colonization. Indeed, it is essential to obtain a sustainable concrete submitted to aggressive marine environment (chloride ions diffusion and bio-colonisation). Four concrete formulations were tested with two types of cements (CEMII and CEMV) and with or without the incorporation of shell aggregates. The durability of these materials was tested after 3 months of immersion in the Rance of Dinard (France). It appears from this study that the CEMII concrete exhibits a good mechanical resistance independently of the presence of shell, after immersion in situ. This concrete also shows better resistance to chloride ions diffusion than CEMV. However, CEMV possess larger compressive strengths than CEMII, and mollusc shells incorporation does not decrease this strength as much as for CEMII. Shell incorporation in the concretes has an effect on strength, chloride penetration and porosity which depend on the used cement and seawater.
\end{abstract}

Keywords: Flat Oyster Larvae, Marine Infrastructure, Concrete, Bio-Colonisation, Durability.

\section{Introduction}

Coastal areas play a crucial role in the economic, social and political development of most countries. As a result, the maritime coasts are increasingly urbanized. Indeed, human activities (ports, tourism, fishing ...) require maritime structures and infrastructures which are often made of concrete. These coastal developments are responsible for the loss of many marine species habitats (Firth et al., 2013, 2014).It is therefore important to offset the residual impacts by generating an equivalent gain in biodiversity.

This study is carried out within the framework of the European Marineff project, which is part of this context. One of this study's objectives is the design of maritime infrastructures for flat oysters (Ostrea edulis Linnaeus, 1758) restoration in the Channel. Indeed, the flat oyster is an endangered species.

Over the years, a new approach has emerged, in the aim of enhancing marine infrastructure (surface condition, structure and composition) to promote ecological succession (Firth et al., 
2014; Perkol-Finkel and Sella, 2014; Sella and Perkol-Finkel, 2015). Thus, the term "ecological engineering" emerged (Bergen et al., 2001; Dennis et al., 2018; Firth et al., 2014, 2016; Pioch et al., 2018; Strain et al., 2018). The effectiveness of eco-engineering interventions varies according to habitats and marine biological communities. Indeed, each marine organism has a different response depending on the infrastructure (Coombes et al., 2015; Hanlon et al., 2018; Jones et al., 1994).

One of the solutions could therefore be the design of bio-receptive and sustainable concrete for the implementation of these infrastructures. Concrete immersed in the marine environment will undergo chemical, physical and biological attacks that can lead to its deterioration (BastidasArteaga et al., 2008; Sanchez-Silva and Rosowsky, 2008). It is therefore important to design concrete that is as durable as possible in order to ensure its sustainability in its immersion environment.

Using a combination of laboratory and field experiments, we aimed to: (1) develop and optimize concrete formulations by varying the type of cement and introducing shellfish byproducts into their composition (2) determine which concrete formulation is the most sustainable following the colonization of marine organism.

\section{Material and Methods}

\subsection{Concrete's Formulations}
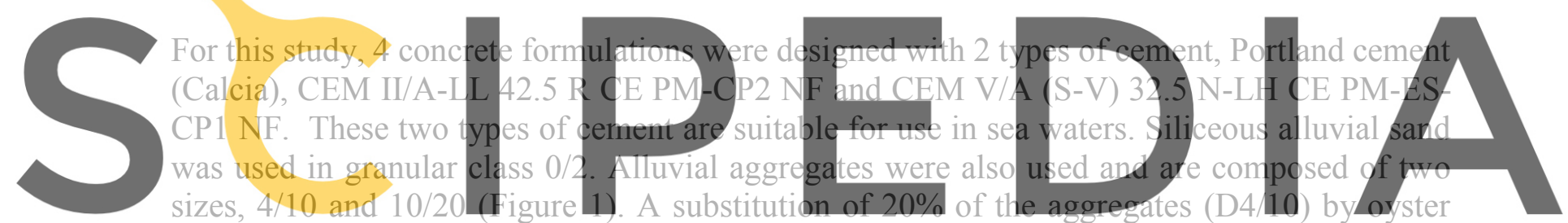

shell aggregates was made to study the effect of this biomineral by-product on the recruitment

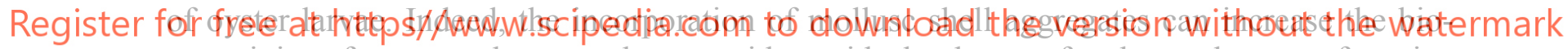
receptivity of concrete because they provide an ideal substrate for the settlement of marine organisms (Graham et al., 2017; Hanlon et al., 2018).

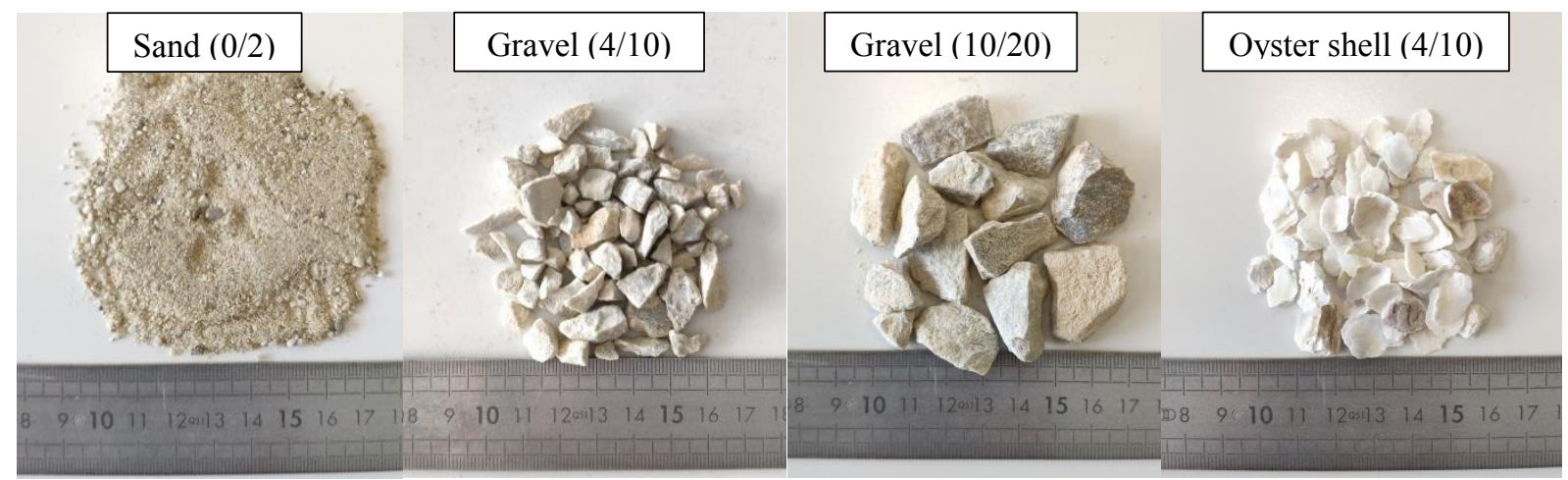

Figure 1. The various types of aggregates used to elaborate the concretes of this study. 
After the characterization of the raw materials, concrete mix designs formulation was carried out in accordance with EN 206-1. The four studied concrete formulations are given in Table 1.

Table 1. Concrete's formulations (Proportions given in $\mathrm{kg} / \mathrm{m}^{3}$ of concrete).

\begin{tabular}{ccccc}
\hline & $\begin{array}{c}\text { F1 : CEM II } \\
\text { without shell }\end{array}$ & $\begin{array}{c}\text { F2 : CEM II with } \\
20 \% \text { shell }\end{array}$ & $\begin{array}{c}\text { F3 : CEM V } \\
\text { without shell }\end{array}$ & $\begin{array}{c}\text { F4 : CEM V with } \\
20 \% \text { shell }\end{array}$ \\
\hline Components & 350 & 350 & 350 & 350 \\
\hline Sand & 800 & 800 & 800 & 800 \\
\hline Gravel 4/10 & 600 & 479 & 600 & 479 \\
\hline Gravel 10/20 & 500 & 500 & 500 & 500 \\
\hline Shell & - & 121 & - & 121 \\
\hline Water & 175 & 175 & 175 & 169 \\
\hline Superplastifiant & $1.28 \%$ & $2 \%$ & $1.28 \%$ & $2 \%$ \\
\hline
\end{tabular}

\subsection{Concrete Durability Against Marine Environment}

To study the sustainability of the concretes in marine environment, 11-cm diameter cylindrical samples with heights of either $22 \mathrm{~cm}$ or $5 \mathrm{~cm}$ were elaborated. Before their immersion in the

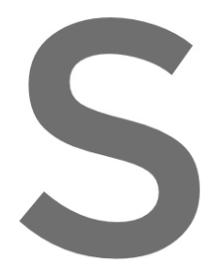
Rance river of Dinard. (France), the samples were
was carried out during 3 months to study marine
this period, mechanical and durability tests were
2.2.1 Compression test
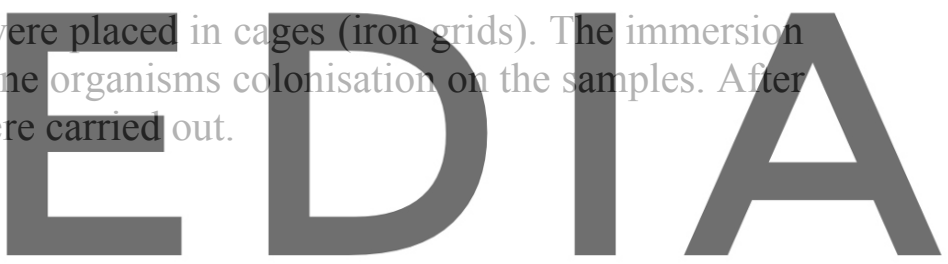

The compression tests were carried out on the $11 \mathrm{~cm} \times 22 \mathrm{~cm}$ cylindrical samples using a 3R

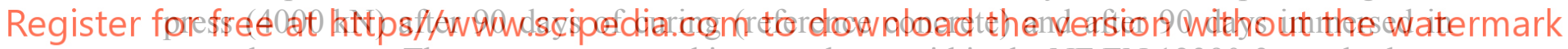
natural seawater. The test was operated in accordance within the NF EN 12390-3 standard.

\subsubsection{Chloride ion diffusion tests}

Ion chromatography was used to measure chloride ions concentrations for a total depth of $1 \mathrm{~cm}$ into the samples (using a $2 \mathrm{~mm}$ step). The powder produced by drilling was collected, filtered and diluted to $1 / 25^{\text {th }}$ before being analyzed by a 883 Basic IC Ion Chromatograph using standard preparation procedures. The obtained leachate is also used to measure the $\mathrm{pH}$ of the material. This test was carried out on the samples immersed natural seawater and in artificial seawater.

\subsubsection{Porosity accessible to water}

Porosity is an important factor that influences the material's durability. This test was carried out on the immersed samples (natural seawater) and after 90 days of curing (reference concrete), according to the NF P18-459 standard.

The value of the porosity (p) is obtained by the equation (1): 


$$
\mathrm{p}=\frac{M_{s d s}-M_{d}}{M_{s d s}-M_{w}} \times 100
$$

Where $M_{s d s}$ is the saturated dry surfaces sample mass, $M_{d}$ the dry sample mass and $M_{w}$ the mass in water.

\section{Results and Discussion}

In order to choose the best concrete formulation, several mechanical strength and durability tests were carried out. The $11 \times 22$ samples were colonised by sessile fauna and some macroalgae after 3 months of immersion in natural seawater. We could count some bryozoans, sponges, serpulid and spiral tubes of Spirorbs (Figure 2).

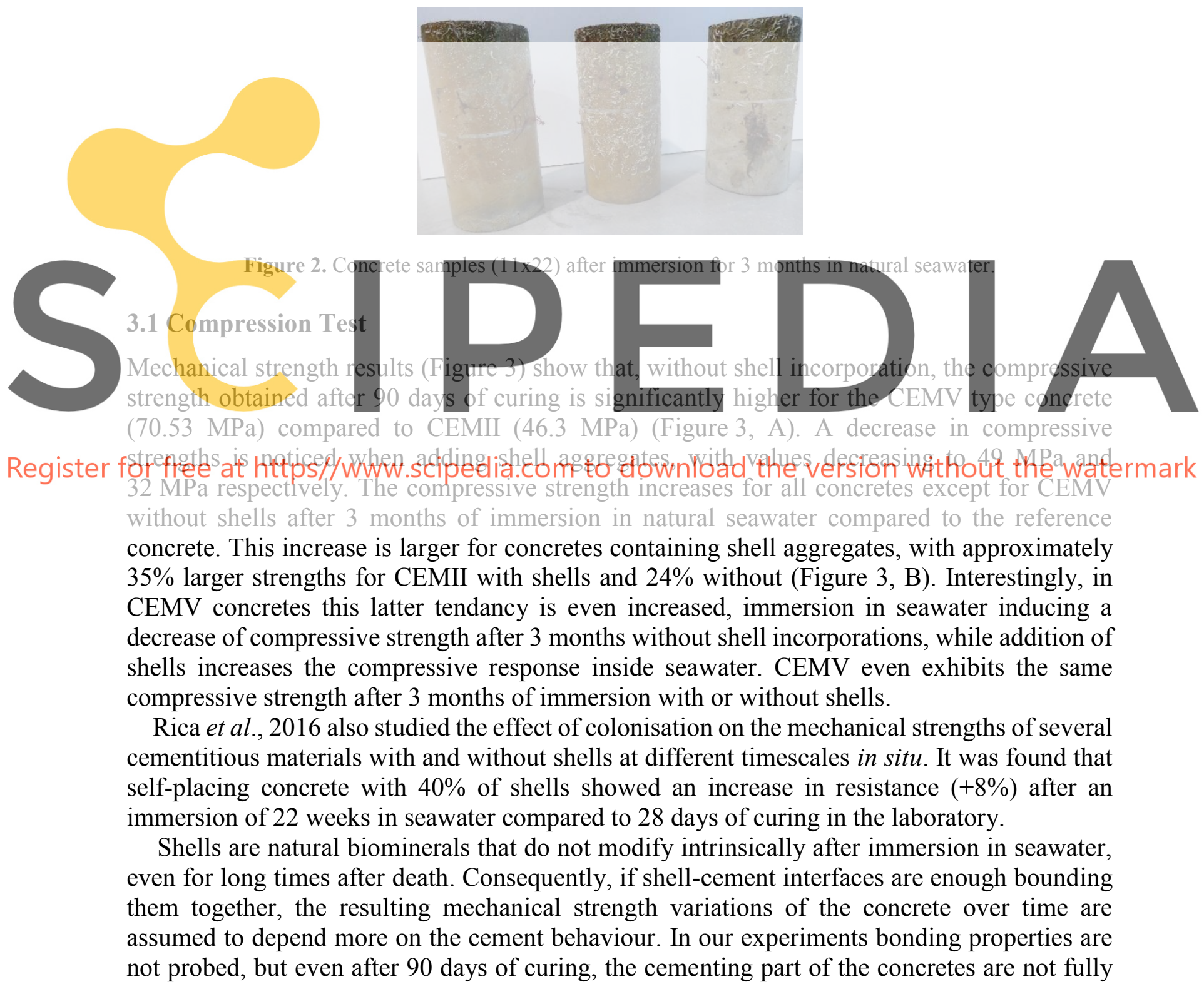


matured and are potentially subjected to suffer some alteration in the aggressive seawater medium. This is at least the case for CEMV which exhibits a clear decrease in compressive strength after 3 months of immersion, and contraily to CEMII. But in shell-containing concretes compressive strength increase is observed for the two types of concretes. The effect of shell incorporation cannot be a simple steric effect with less deterioration thanks to shell additions, since this would only reduce the compressive strength decrease of CEMV comparing with and without shell.

We are then concluding that another effect occurs, beneficial to and not only buffering strength decrease. The mechanism for such an effect is not monitored by our experiments, and further investigations are needed to explain our results. A modification of the concrete microstructure due to calcium carbonates and organic species contained in the shells could be at the origin of the observed behaviour.

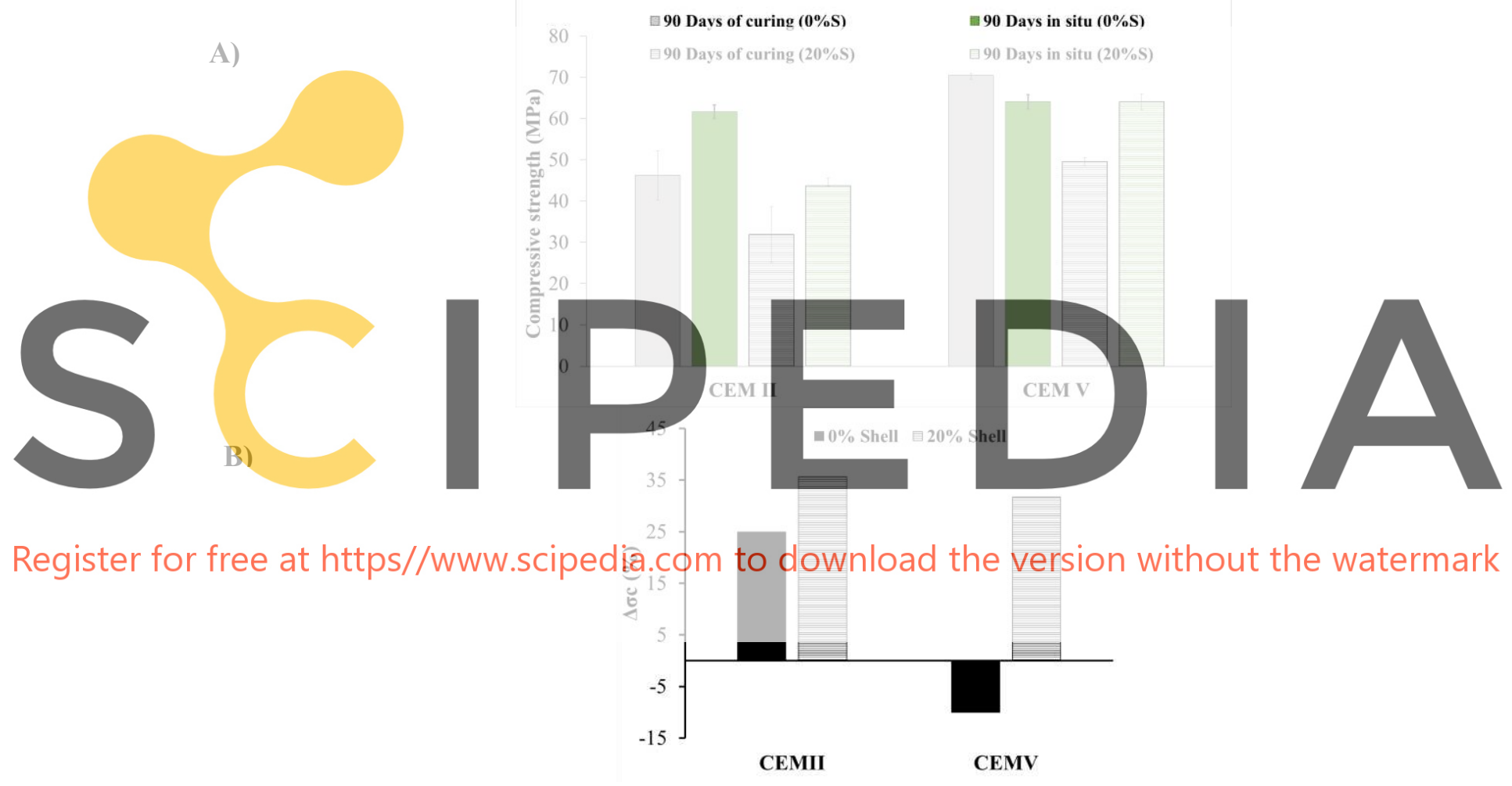

Figure 3. (A): Compressive strength of the different concrete formulations after 90 days of curing and after 90 days in natural seawater; (B) : Difference between the resistance of concretes immersed in seawater for 90 days vs. cured at $100 \%$ RH (90 days).

\subsection{Chloride Ion Diffusion Tests}

The durability of concrete mix designs against chloride ions diffusion were then studied after immersion in two different environments: artificial and natural seawaters. The evolution of the chloride ions content (as a function of depth and environment) is represented in Figure 4. We can also notice that after 3 months of immersion in natural seawater, we obtain higher chloride ions content between 0 and $6 \mathrm{~mm}$ for the concrete mix designs manufactured without shells 
compared to those immersed in artificial seawater (Figure $4 \mathrm{~A}$ and $\mathrm{C}$ ). This result can be explained by the fact that the bio-colonisation of samples facilitates the penetration of $\mathrm{Cl}^{-}$ions.

In artificial seawater (ASW, Figure 4, solid lines), the presence of shells in the concrete (Figure 4B and D) tends to enhance chloride content by a factor of nearly 2 in the first millimeters compared to concretes without shells (Figure 4A and C). This tendancy is not observed for immersions in natural seawaters (NSW, dotted lines). The reason for such a behaviour could be seen in partial dissolution of shell pieces, which is more pronounced in artificial seawaters. Part of the molecules and macromolecules contained in shells are Water Soluble (WSM), and present in NSW but not in ASW. Consequently, immersing shells in ASW gives rise to larger chemical potentials than in NSW, tending to operate more dissolution and element infiltrations, the process being or not mediated by chloride ions.

The total chloride content in our concretes varies according to the cement type. In the first six millimetres, whatever the used conditions (with and without shells, seawater) the concretes made with CEMII are more sustainable from the point of view of chlorine penetration than those elaborated with CEMV. For CEMII, chloride content does not exceed 1500 ppm in the first millimetres (Figures 4A and B), while in CEMV (Figure 4C and D) this concentration is at least twice this amount (up to $3700 \mathrm{ppm}$ ).
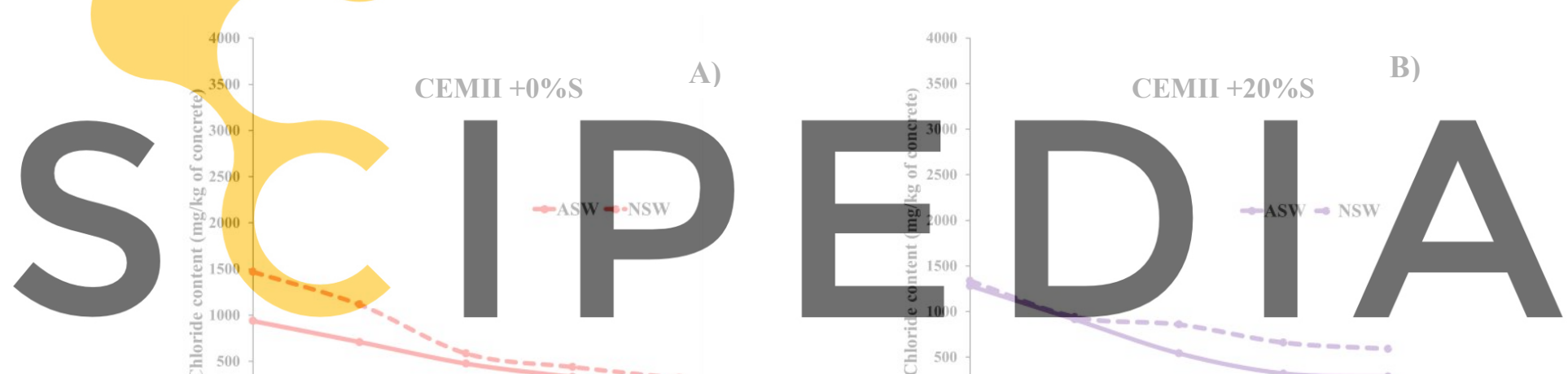

Register for free at https//www.scipedia.com to download the version without the watermark

Depth from surface $(\mathrm{mm})$

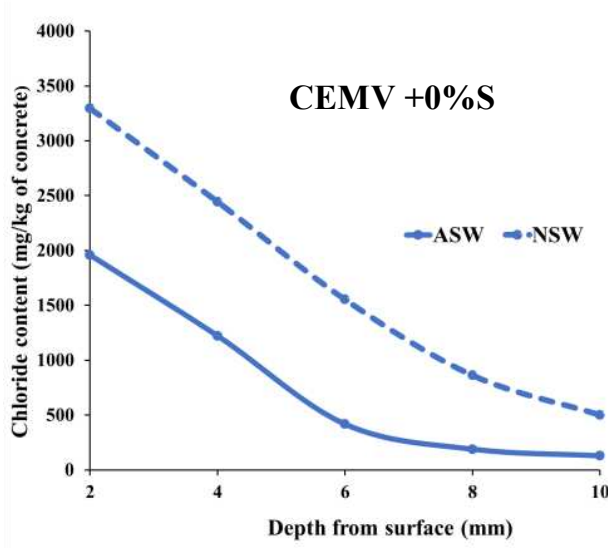

C)

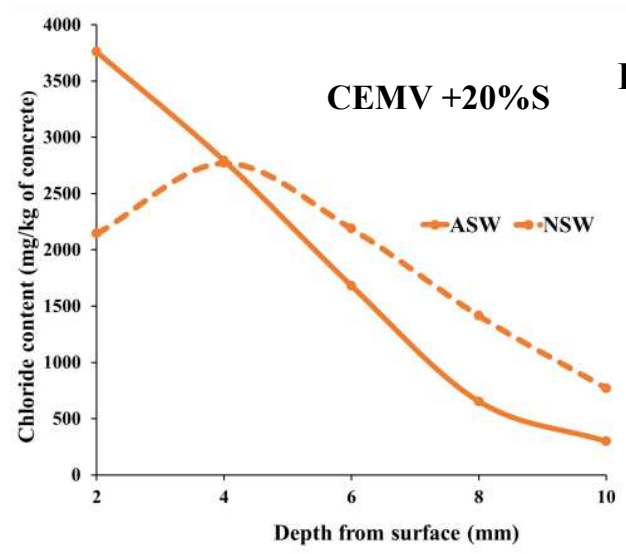

Figure 4. Chloride ions content after an immersion of 1 month in Artificial SeaWater (ASW) (solid line) and after 3 months in Natural SeaWater (NSW) (dotted line) for two different concrete composition CEMII and CEMV without Shells (S) (Respectively A et C) and CEMII and CEMV with Shells (Respectively B et D). 


\subsection{Porosity Accessible to Water}

Measurements of porosity accessible to water (Figure 5) indicate that, except for a slight increase in porosity of around $0.1-0.2 \%$, the two concrete formulations made with CEMII remain stable after immersion for 3 months in natural seawater. This is not the case for CEMV concretes for which we observe a decrease of porosity up to $4 \%$ after 3 months. The shellcontaining CEMV concrete however exhibit less porosity decrease compared to such a concrete without shells. Such porosity decrease contributes undoubtfully to the compressive strength increase of the CEMV sample with shells.

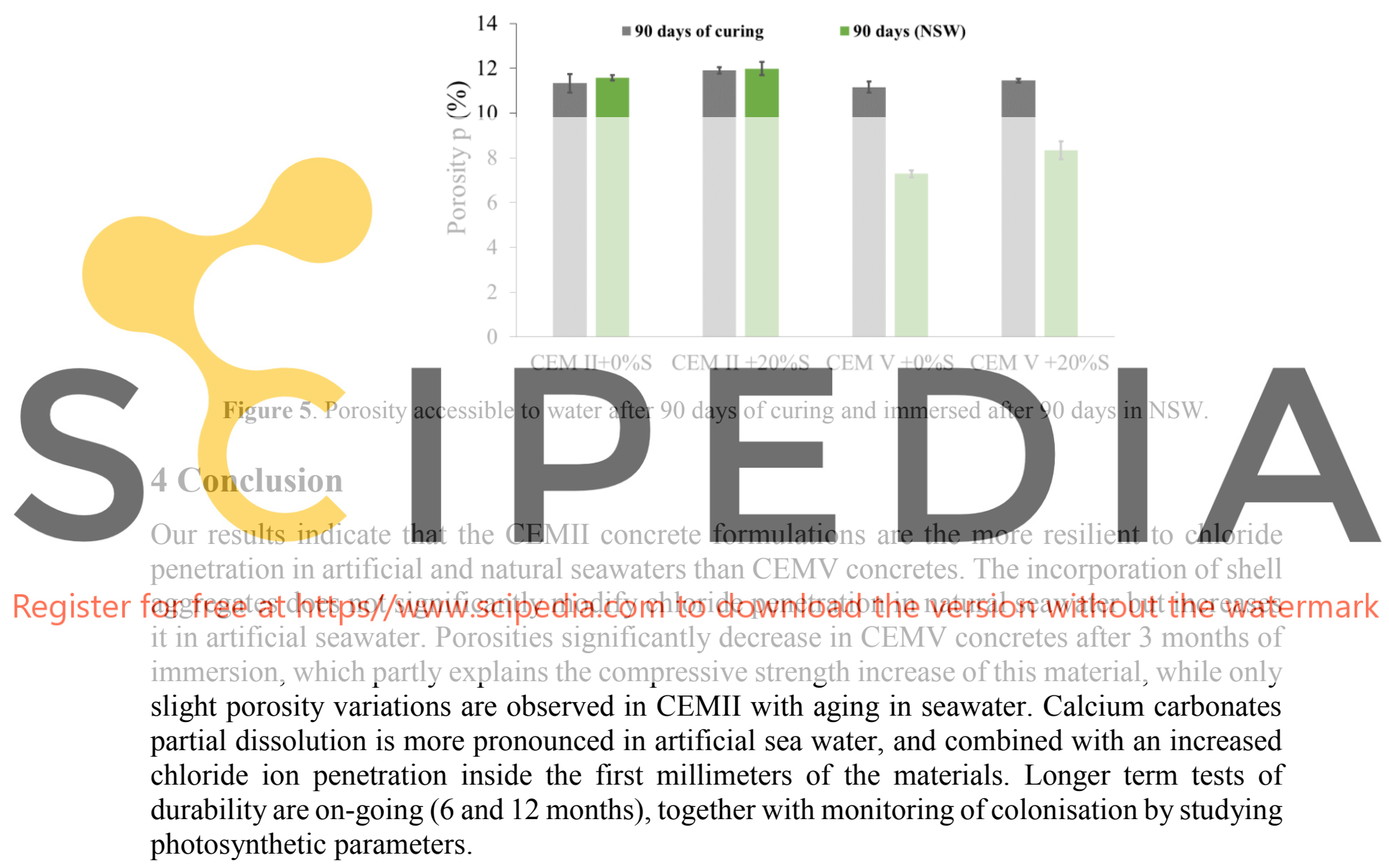

\section{Acknowledgements}

We would like to thank the MNHN (Natural History National Museum) of Dinard for allowing us to immerse the concrete samples and have recover them after 3 months of immersion in the Rance of Dinard. Thanks to the Lucsur-Mer Marine Station (Université de Caen Normandie) for allowing us to immerse our concrete samples for the long term tests.

\section{ORCID}

Nassim Sebaibi: http://orcid.org/0000-0002-1241-2745

Daniel Chateigner: http://orcid.org/0000-0001-7792-8702

Mohamed Boutouil: http://orcid.org/0000-0002-2752-8265 


\section{References}

Bastidas-Arteaga, E., Sánchez-Silva, M., Chateauneuf, A., and Silva, M.R. (2008). Coupled reliability model of biodeterioration, chloride ingress and cracking for reinforced concrete structures. Struct. Saf. 30, 110-129.

Bergen, S.D., Bolton, S.M. and L. Fridley, J. (2001). Design principles for ecological engineering. Ecol. Eng. 18, 201-210.

Coombes, M.A., La Marca, E.C., Naylor, L.A. and Thompson, R.C. (2015). Getting into the groove: Opportunities to enhance the ecological value of hard coastal infrastructure using fine-scale surface textures. Ecol. Eng. 77, 314-323.

Dennis, H.D., Evans, A.J., Banner, A.J. and Moore, P.J. (2018). Reefcrete: Reducing the environmental footprint of concretes for eco-engineering marine structures. Ecol. Eng. 120, 668-678.

Firth, L.B., Mieszkowska, N., Thompson, R.C. and Hawkins, S.J. (2013). Climate change and adaptational impacts in coastal systems: the case of sea defences. Environ. Sci. Process. Impacts 15, 1665-1670.

Firth, L.B., Thompson, R.C., Bohn, K., Abbiati, M., Airoldi, L., Bouma, T.J., Bozzeda, F., Ceccherelli, V.U., Colangelo, M.A., Evans, A., et al. (2014). Between a rock and a hard place: Environmental and engineering considerations when designing coastal defence structures. Coast. Eng. 87, 122-135.

Firth, L.B., Browne, K.A., Knights, A.M., Hawkins, S.J. and Nash, R. (2016). Eco-engineered rock pools: a concrete solution to biodiversity loss and urban sprawl in the marine environment. Environ. Res. Lett. 11, 094015.

Graham, P.M., Palmer, T.A. and Pollack, J.B. (2017). Oyster reef restoration: substrate suitability may depend on specific restoration goals. Restor. Ecol. 25, 459-470.

Hanlon, N., Firth, L.B. and Knights, A.M. (2018). Time-dependent effects of orientation, heterogeneity and composition determines benthic biological community recruitment patterns on subtidal artificial structures. Ecol. Eng. 122, 219-228

Jones, C.G., Lawton, J.H. and Shachak, M. (1994). Organisms as Ecosystem Engineers. Oikos 69, 373-386.

NF EN 206+A1, Concrete-

NF EN 12390-3, Testing har

NF P18-459, Concrete - T

Perkol-Finkel, S. and Sella,

Innovative Matrices and pp. 1139-1149.

Pioch, S., Relini, G., Souche, J.C., Stive, M.J.F., De Mo
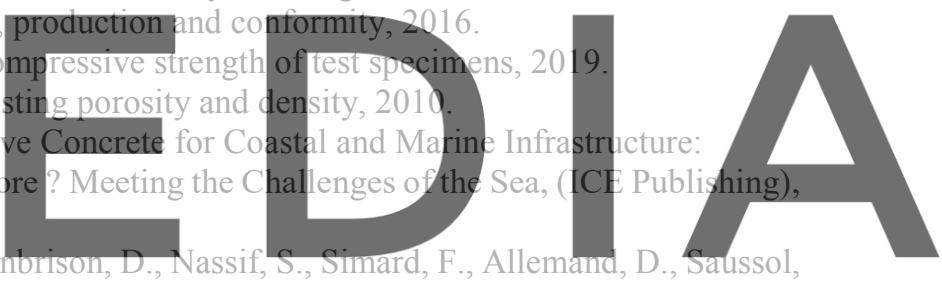

P., Spieler, R., et al. (2018). Enhancing eco-engineering of coastal infrastructure with eco-design: Moving from

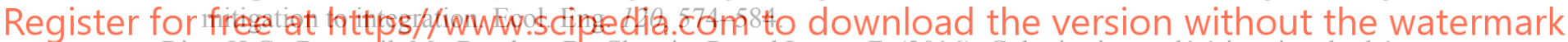

Rica, H.C., Boutouil, M., Boudart, B., Claquin, P. and Leroy, F. (2016). Colonisation et détérioration des bétons incorporant des coquilles pour récifs artificiels. Matér. Tech. 104, 503.

Sanchez-Silva, M. and Rosowsky, D.V. (2008). Biodeterioration of Construction Materials: State of the Art and Future Challenges. J. Mater. Civ. Eng. 20, 352-365.

Sella, I. and Perkol-Finkel, S. (2015). Blue is the new green - Ecological enhancement of concrete based coastal and marine infrastructure. Ecol. Eng. 84, 260-272.

Strain, E.M.A., Olabarria, C., Mayer-Pinto, M., Cumbo, V., Morris, R.L., Bugnot, A.B., Dafforn, K.A., Heery, E., Firth, L.B., Brooks, P.R., et al. (2018). Eco-engineering urban infrastructure for marine and coastal biodiversity: Which interventions have the greatest ecological benefit? J. Appl. Ecol. 55, 426-441. 